\title{
The Product Produced by Interaction of the Cis-diammin(cyclobutane 1,1 dicarboxylato) Platinum(II) with Arabinogalactan
}

\author{
Alexander K. Starkova, Galina A. Kozuchovskaya*a, \\ Nina I. Pavlenko a and Sergey D. Kirik ${ }^{\mathrm{b}}$ \\ anstitute of Chemistry and Chemical Technology SB RAS \\ FRC "Krasnoyarsk Science Center SB RAS" \\ 50/24 Akademgorodok, Krasnoyarsk, 660036, Russia \\ ${ }^{b}$ Siberian Federal University \\ 79 Svobodny, Krasnoyarsk, 660041, Russia
}

Received 09.02.2018, received in revised form 14.03.2018, accepted 27.04.2018

The obtained new product of reaction of the complex cis-diammin (cyclobutane 1,1 dicarboxylato) platinum(II) with arabinogalactan was characterized by XRD, IR-spectroscopy, UF-spectrophotometry and thermogravimetry. The composition and structure of this product was studied. It has been shown that cis-diammin(cyclobutane 1,1 dicarboxylato) platinum(II) associated with arabinogalactan through communications -C-O-C-groups by hydrogen of the original complex.

Keywords: complex compound of platinum, synthesis, physic-chemical properties, arabinogalactan, amines, anticancer activity.

Citation: Starkov A.K., Kozuchovskaya G.A., Pavlenko N.I., Kirik S.D. The product produced by interaction of the cisdiammin(cyclobutane 1,1 dicarboxylato) platinum(II) with arabinogalactan, J. Sib. Fed. Univ. Chem., 2018, 11(2), $211-218$. DOI: $10.17516 / 1998-2836-0069$.

(c) Siberian Federal University. All rights reserved

* Corresponding author E-mail address: kaz@icct.ru 


\title{
Продукт взаимодействия комплекса цис-диамин (циклобутан-1,1-дикарбоксилат-О,О') платина(II) \\ с арабиногалактаном
}

\author{
А.К. Старков ${ }^{a}$, Г.А. Кожуховская ${ }^{a}$, \\ Н.И. Павленко ${ }^{a}$, С.Д. Кирик ${ }^{6}$ \\ ${ }^{a}$ Институт химии и химической технологии СО РАН \\ ФИЦ «Красноярский научный иентр СО РАН» \\ Россия, 660036, Красноярск, Академгородок, 50/24 \\ ${ }^{6}$ Сибирский федеральный университет \\ Россия, 660041, Красноярск, пр. Свободный, 79
}

Получен продукт взаимодействия комплекса иис-диамин(ииклобутан-1,1-дикарбоксилатO,O) платина(II) с арабиногалактаном, который охарактеризован методами РФА, рентгенофлуоресиентным, ИК-спектроскопии, термогравиметриии УФ-спектрофотоментии, установлен его состав. Показано, что ичи-диамин(ияклобутан-1,1-дикарбоксилат-О,O') платина(II) предположительно связан с арабиногалактаном водородными связями, образованными группами -C-O-C- и $\mathrm{NH}_{3}$-группами исходного комплекса.

Ключевые слова: комплексное соединение платины, синтез, физико-химические свойства, амины и арабиногалактан.

\section{Введение}

Комплексное соединение цис-диамин(циклобутан-1,1-дикарбоксилат-О,О') платина (II) (карбоплатин) является противоопухолевым препаратом второго поколения и с октября 2004 г. применяется в клинической практике [1]. Карбоплатин менее токсичен и более эффективен при лечении злокачественных заболеваний по сравнению с цис-дихлородиаминплатиной (II) (цисплатин). Скорость гидролиза карбоплатина меньше по сравнению с цис-платином, но в растворе присутствуют гидролизованные формы, которые отравляют организм [2-4]. Для исключения гидролизованных форм используется полисахарид арабиногалактан, продукт взаимодействия которого с карбоплатином не гидролизуется. Это открывает перспективу получения новых лекарственных препаратов. При этом арабиногалактан способен формировать коньюганты с различными веществами в виде сферических частиц $[5,6]$. Благодаря этому свойству арабиногалактан может использоваться для доставки внутрь веществ, которые сами плохо проникают в клетку через наружную мембрану, что увеличивает эффективность применяемых противоопухолевых препаратов. В частности, в работе [7] показано, что продукт, полученный на основе взаимодействия цис-платина с арабиногалактаном, обладает способностью более эффективно подавлять рост асцидных клеток карциномы Эрлиха и не оказывает токсичного действия на организм в отличие от цис-платина $[8,9]$.

Полученный продукт взаимодействия карбоплатина с арабиногалактаном также будет обладать биологической активностью. 
В данной статье приводятся результаты по синтезу нового продукта на основе взаимодействия карбоплатина с арабиногалактаном. Проведено его физико-химическое исследование.

\section{Экспериментальная часть}

Синтез исходного комплекса цис-диамин(циклобутан-1,1-дикарбоксилат-О,О') платины(II) (карбоплатина) проведен по методике [10]. Продукт взаимодействия карбоплатина с арабиногалактаном получен по разработанной нами методике [11], несколько модифицированной и усовершенствованной. Для проведения реакции использовался арабиногалактан, выделенный из древесины лиственницы сибирской [12]. Для определения оптимальных условий проведения синтезов перспективной фармакологической субстанции на основе взаимодействия комплексного соединения карбоплатина с арабиногалактаном предварительно спектрофотометрическим методом были изучены процессы протекания реакций при получении продукта. Наши данные позволили оптимизировать концентрационные и температурные условия синтеза нового продукта. 0,025 г карбоплатина добавляли к 1 г арабиногалактана и растворяли в 20 мл воды. Раствор нагревали на водяной бане в течение 30 мин, затем раствор охлаждали и добавляли к нему 60 мл спирта. Выпавший осадок отфильтровывали и сушили. Выход продукта составлял $82 \%$.

Порошковые рентгенограммы регистрировали на дифрактометре X pert Pro (PANalytical, Нидерланды) с геометрией по Бреггу-Брентано, оснащенном полупроводниковым детектором PIXel c графитовым монохроматором. Использовали CuK $\alpha$-излучение. Интервал съемки от 10 до $90^{\circ}$ с шагом $0,026^{\circ}$.

Рентгеновскую флуоресцентную спектроскопию (РФС) проводили с использованием спектрометра «Axios Advanced» (PANalytical, Нидерланды). Спектры регистрировали по всему диапазону длин волн всех элементов таблицы Менделеева, начиная с кислорода. Затем с помощью программы $\mathrm{IQ}^{+}$проводили полуколичественный анализ элементов. Чувствительность метода $-0,01 \%$, точность $5 \%$.

ИК-спектры соединений регистрировали на ИК-Фурье спектрометре IRTracer - 100 (Shimadzu, Япония) в области 4000-400 см-1. Образцы для съемки спектров готовили в матрице бромистого калия с навеской исследуемого образца 3,0 мг (навеска матрицы постоянна и равна 1 г). Условия приготовления образцов (время перемешивания с бромистым калием, давление прессования, время вакуумирования) одинаковы, толщины полученных таблеток постоянны (в пределах величины $(1,150 \pm 0,005)$ мм). Обработка спектральной информации осуществлялась с применением пакета программ LabSolution IR. Собственное поглощение таблетки бромистого калия перед обработкой спектров образцов вычтено. Исследуемые образцы представляют собой смеси свободного арабиногалактана и комплекса платины. Для исключения полос поглощения свободного арабиногалактана в анализируемой смеси получены дифференциальные спектры с использованием подпрограммы «Spectrum Subtraction».

Термограммы соединений получали на приборе NET2SCH STA 449 C с анализатором для отходящих газов в воздушной атмосфере. Нагревание проводили в интервале температур от 20 до $1000{ }^{\circ} \mathrm{C}$ со скоростью $10^{\circ} \mathrm{C}$ в минуту. Масса навесок комплексов составляла 10 мг.

Электронные спектры поглощения снимали на спектрофотометре «Specord UV-VIS». Применяли процедуру сканирования спектров в области 28000-46000 см-1.

$$
-213-
$$




\section{Результаты и обсуждение}

Впервые полученный продукт был изучен методами РФА, ИК-спектроскопии, термогравиметрии, УФ-спектрофотометрии и рентгено-флуоресцентным анализом.

Результаты рентгенофазового анализа представлены на рис. 1. Приведенная на рис. 1 рентгенограмма 1 соответствует кристаллической фазе исходного карбоплатина. Рентгенограмма 2 представляет собой механическую смесь карбоплатина с содержанием платины 1,3% с арабиногалактаном. Рентгенограмма 3 - продукт взаимодействия соли карбоплатина с арабиногалактаном. Известно, что арабиногалактан рентгеноаморфен. На рис. 1 (рентгенограмма 3) видно, что у полученного продукта кристаллическая фаза карбоплатина не проявляется по сравнению с механической смесью (рентгенограмма 2).

Согласно рентгенофлуоресцентному исследованию, продукт взаимодействия карбоплатина с арабиногалактаном содержит платину.

Сделано предположение, что в полученном продукте карбоплатин связывается с арабиногалактаном через аминогруппу.

Аналогичный вывод следует и из результатов ИК-спектроскопического исследования образцов. Разностный спектр, полученный после вычитания из ИК-спектра механической смеси спектра арабиногалактана, идентичен спектру исходного карбоплатина [13]. В области валентных колебаний $\mathrm{NH}_{3}$-групп наблюдается три полосы при 3268, 3189 и $3145 \mathrm{~cm}^{-1}$ и полосы колебания $-\mathrm{C}=\mathrm{O}-$ групп при 1612 и $1595 \mathrm{~cm}^{-1}$. Однако в разностном спектре полученный аморфный продукт минус арабиногалактан фаза исходного карбоплатина не обнаружена.

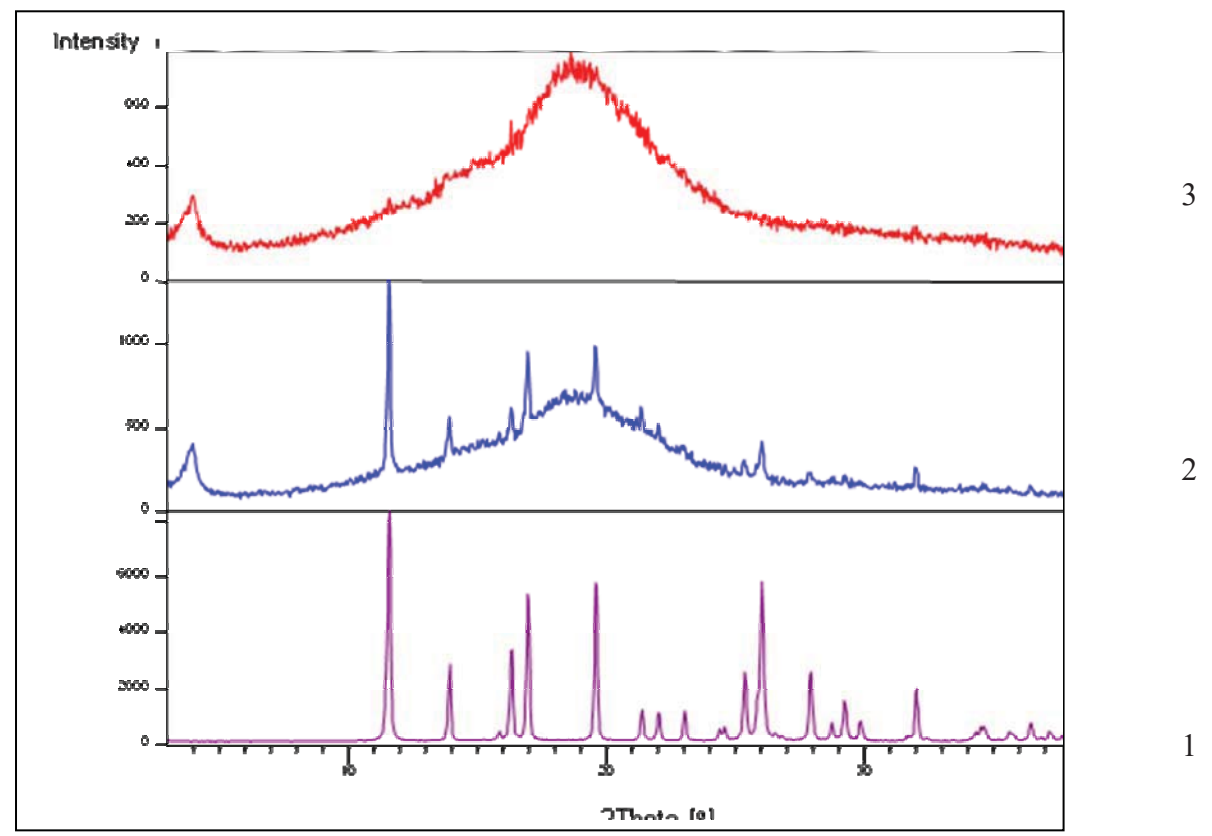

Рис. 1. Рентгенограммы: 1 - карбоплатина; 2 - механической смеси карбоплатина (1,3 \% по платине) и арабиногалактана; 3 - продукта взаимодействия карбоплатина (1,3 \% по платине) с арабиногалактаном

Fig. 1. X-rays: 1 - carboplatin; 2 - mechanical mixture of carboplatin (1.3\% of platinum) and arabinogalactan; 3 - product of the interaction of carboplatin (1.3\% of platinum) with arabinogalactan 
Данный результат также свидетельствует о наличии в продукте связи карбоплатина с арабиногалактаном.

Термограммы арабиногалактана и полученного продукта приведены на рис. 2-4. На кривой ДСК для арабиногалактана (рис. 2) наблюдаются два экзоэффекта при температурах 333 и $478^{\circ} \mathrm{C}$, связанные со ступенчатым распадом арабиногалактана. На рис. 3 приведена термограмма механической смеси карбоплатина с арабиногалактаном. Наличие на кривой ДСК трех экзоэффектов при температурах 269, 298 и $444{ }^{\circ} \mathrm{C}$ свидетельствует о том, что первые два пика относятся к распаду карбоплатина, а третий - к распаду арабиногалактана. На рис. 4

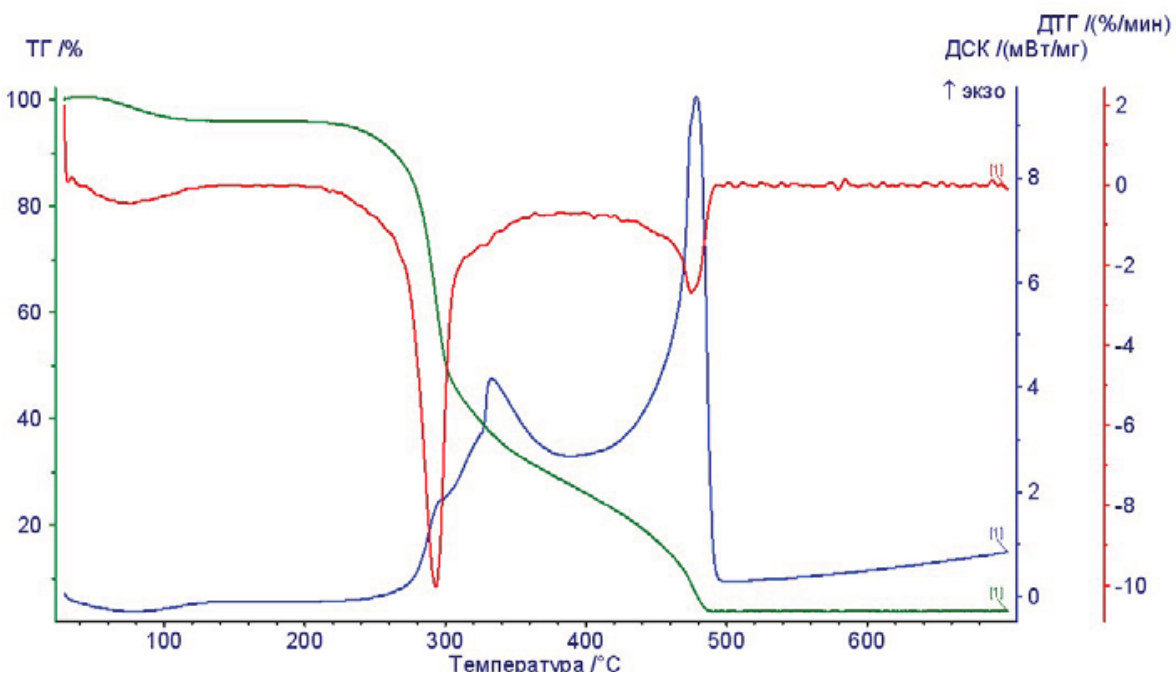

Рис. 2. Термограмма арабиногалактана

Fig. 2. Thermogram of arabinogalactan

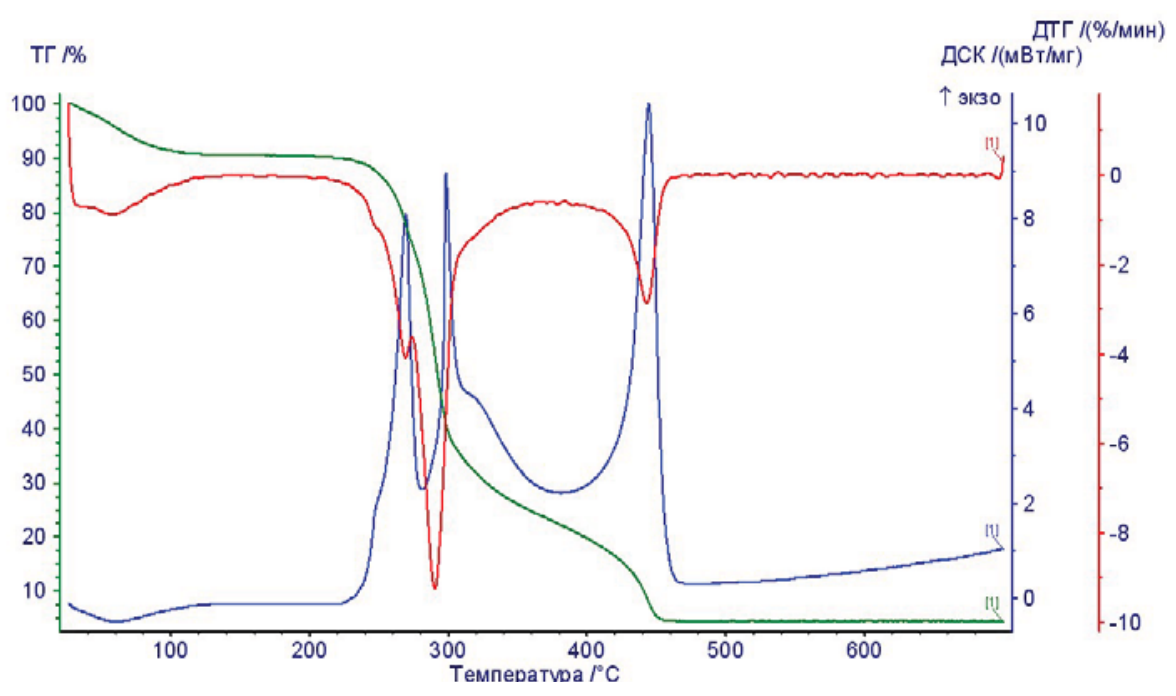

Рис. 3. Термограмма механической смеси карбоплатина и арабиногалактана

Fig. 3. Thermogram of mechanical mixture of carboplatin and arabinogalactan 
приведена термограмма продукта взаимодействия карбоплатина с арабиногалактаном. На кривой ДСК имеется один экзоэффект при температуре $314{ }^{\circ} \mathrm{C}$. Увеличение тепловых эффектов при разложении смеси карбоплатина и арабиногалактана и продукта (рис. 3 и 4) по сравнению с арабиногалактаном (рис. 2) связано с различием в механизме окисления углерода при разложении. Такие эффекты достигаются за счет присутствия карбоплатина в смеси и продукте по сравнению с арабиногалактаном. Наличие одного экзоэффекта в продукте (рис. 4) по сравнению с механической смесью (рис. 3) указывает на то, что получено соединение карбоплатина с арабиногалактаном. Из кривой ТГ рассчитано содержание платины в продукте. Оно составляет $1,3 \%$.

В таблице приведены УФ-спектры исходного карбоплатина, арабиногалактана и полученного продукта на основе взаимодействия карбоплатина с арабиногалактаном.

Как видно из таблицы, молярные коэффициенты поглощения карбоплатина небольшие. Их вклад в спектр полученного продукта незначителен. В то же время молярные коэффициенты поглощения для полученного продукта выше, чем у арабиногалактана. Данный факт также свидетельствует о том, что этот продукт не является механической смесью карбоплатина и арабиногалактана.

\section{Заключение}

Впервые синтезирован продукт взаимодействия комплекса карбоплатина с арабиногалактаном. Продукт изучен методами РФА, ИК-спектроскопией и термогравиметрией.

Совокупность вышеизложенных результатов позволяет предположить, что взаимодействие комплекса карбоплатина с арабиногалактаном приводит к образованию продукта, в котором предположительно комплекс связан с арабинозой арабиногалактана по связи -C-O- С- с водородом $\mathrm{NH}_{3}$ группы исходного комплекса.

Полученный продукт предполагается исследовать на биологическую активность.

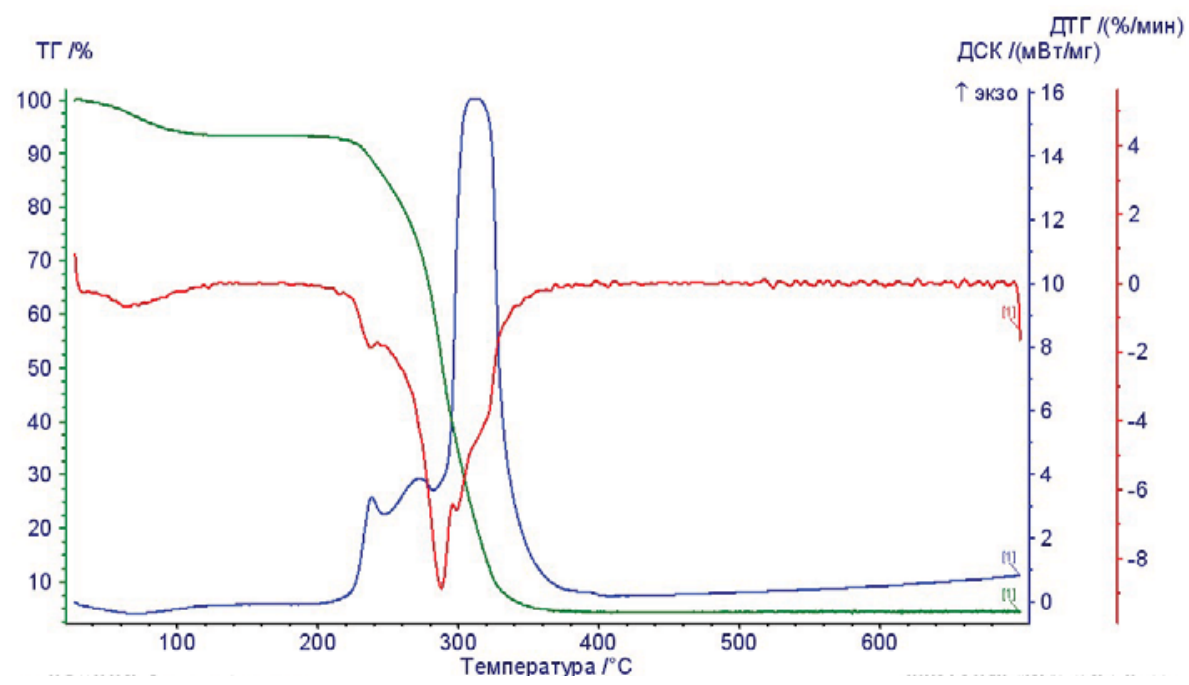

Рис. 4. Термограмма продукта взаимодействия карбоплатина с арабиногалактаном

Fig. 4. Thermogram of product of the interaction of carboplatin with arabinogalactan

$$
-216-
$$


Таблица. Молярные коэффициенты поглощения $\varepsilon$, л/(моль·см) комплексов цис-платин, карбоплатин и продуктов, полученных их взаимодействием с арабиногалактаном

Table. Molar absorption coefficients $\varepsilon, 1 /(\mathrm{mol} \cdot \mathrm{cm})$ of cis-platinum, carboplatin complexes and products obtained by their interaction with arabinogalactane

\begin{tabular}{|c|c|c|c|}
\hline $\begin{array}{l}v \cdot 10^{3} \\
\mathrm{~cm}^{-1}\end{array}$ & $\begin{array}{c}\text { Карбоплатин, } \varepsilon, \\
\text { л/(моль•см) }\end{array}$ & $\begin{array}{c}\text { Арабиногалактан } \varepsilon, \\
\text { л/(моль·см) }\end{array}$ & $\begin{array}{c}\text { Продукт, полученный взаимодействием } \\
\text { карбоплатина с арабиногалактаном, } \varepsilon, \\
\text { л/(моль·см) }\end{array}$ \\
\hline 37 & 68 & 2094 & 2245 \\
\hline 36 & 48 & 2222 & 2372 \\
\hline 35 & 36 & 2320 & 2479 \\
\hline 34 & 26 & 2158 & 2390 \\
\hline 33 & 21 & 1872 & 1991 \\
\hline 32 & 21 & 1517 & 1652 \\
\hline 31 & 19 & 1196 & 1356 \\
\hline 30 & 17 & 1024 & 1110 \\
\hline 29 & 13 & 854 & 932 \\
\hline 28 & 9 & 726 & 771 \\
\hline
\end{tabular}

Работа выполнена с использованием оборудования ЦКП Красноярского научного центра Сибирского отделения Российской академии наук.

\section{Список литературы}

1. Wilson J.J., Lippard S.J. Synthetic Methods for the Preparation of Platinum Anticancer Complexes. Chemical Reviews 2014. Vol. 114(8), P. 4470-4495.

2. Faggiani R., Lippert B., Lock C., Rosenberg A. Hydroxo-Bridged Platinum (II) Complexes. 1. Di- $\mu$-hydroxo-bis[diamineplatinum(II)] Nitrate. Crystalline Structure and Vibrational Spectra. Journal of the American Chemical Society 1977. Vol. 2, P.778-781.

3. Clear M.J., Hoeschele J.D. Studes on the Anttumor Activity of group VIII. Transition Metal complexes. Part I. Platinum(II) Complexes. Bioinorganic Chemistry 1973. Vol. 2, P. 187-209.

4. Signozzi C.A., Bantocci C., Ossicini L., Maldotti A. Fotochemistry of dimeric and trimeric hydroxbridged diamminoplatinum(II) complexes in solution. Inorganica Chimica Acta 1982. Vol. 82, P.187-191.

5. Арифходжаев А.Д. Галактан и галактансодержащие полисахариды высших растений. Химия природных соединений 2000. № 3, С. 183-191. [Arifchodzaev A.D. Galactan and galactane containing polisacharides of higher plants. Chemistry of natural compounds 2000. No.3, P. 183-191. (In Russ.)]

6. Grieshop C.M., Flickiger E.A., Fahey G.C. Oral administration of arabinogalactan affects immune status and fecal microbial populatione delivery. Journal of Nutrition 2002. Vol. 132(3), P. 478485 .

7. Старков А.К., Замай Т.Н., Савченко А.А., Инжеваткин Е.В., Титова Н.М., Кловская О.С., Лузан Н.А., Силкин П.П., Кузнецова С.А. Противоопухолевый эффект комплекса арабиногалактана с платиной. Доклады Академии наук 2016. Т. 467(1), С. 112-114. [Starkov A.K., Zamai T.N.,

$$
-217-
$$


Savchenko A.A., Inzhevatkin E.V., Titova N.M., Kolovskaya O.S., Lusan N.A., Silkin P.P., Kuznecova S.A. The antitumor effect of complex arabinogalactan with platinum. Russian Journal Doklady Akademii Nauk 2016. Vol. 467(1), P.112-114.(In Russ.)]

8. Старков А.К., Кожуховская Г.А., Павленко Н.И. Получение и идентификация препарата взаимодействия соли цис-дихлородиамминплатины(II) с арабиногалактаном и его терапевтическое действие. Координачионная химия 2014. Т.40 (9), С.575. [Starkov A.K., Kozuchovskaya G.A., Pavlenko N.I. Obtaining and identification of the drug of reaction the solt cis-dichlorodiammplatinum (II) with arabinogalactan and its therapeutic action. Russian Journal of Coordination Chemistry 2014. Vol. 40(9), P.575. (In Russ.)]

9. Старков А.К., Кожуховская Г.А., Павленко Н.И. Продукт взаимодействия комплекса цис-дихлородиамминплатины (II) с матрицей-носителем арабиногалактаном и его свойства. Журнал СФУ. Химия 2015, Т. 8(2), С. 269-276. [Starkov A.K., Kozuchovskaya G.A., Pavlenko N.I. The reaction product of the complex cis-dichlorodiammplatinum (II) with matrix carrier arabinogalactan and its properties. Journal of Siberian Federal University. Chemistry 2015. Vol. 8(2), P. 269-276. (In Russ.)]

10. Патент 2330039 РФ. Мамонов С.Н. Способ получения цис-диаммино (циклобутан-1,1дикарбоксилат-О,O')платина(II). Опубл. 27.07.2008. [Patent 2330039 RU. Mamonov C.N. A method of producing a cis-diammin(cyclobutane 1,1 dicarboxylato) platinum(II). Publ. Date 27.07.2008 (In Russ.)]

11. Патент 2406508 РФ. Старков А.К, Когай Б.Е. Способ получения Pt-производного арабиногалактана. Опубл. 20.12.2010. [Patent 2406508 RU. Starkov A.K., Kogai B.E. A method of producing a arabinogalactan. Publ. Date 20.12.2010 (In Russ.)]

12. Патент 2143437 РФ. Бабкин В.А., Остроухова Л.А., Медведева С.А., Бабкин Д.В., Малков Ю.А., Александрова Г.П., Антонов Л.Н. Способ получения высокочистого арабиногалактана. Опубл. 27.12.1999. [Patent 2143437 RU. Babkin V.A., Ostrouchova L.A., Medvedeva S.A., Babkin D.V., Malkov U.A., Aleksandrova G.P., Antonov L.N. A method of producing a high clean arabinogalactan. Publ. Date 27.12.1999 (In Russ.)]

13. Rafal Wysokinski, Janina Kuduk-Jaworska, Danuta Michalska Electronic structure, Raman and infrared spectra, and vibrational assignment of carboplatin. Density functional theory studies. Journal of Molecular Structure: Theochem 2006. Vol.758, P.169-179. 